\title{
Considerations on oversized transportation in the UE(Community)
}

\author{
Mircea Bădescu ${ }^{1}$, and Carmen Maria Purcar ${ }^{1, *}$ \\ ${ }^{1}$ Lucian Blaga University of Sibiu, Industrial Engineering and Management Department, 10 Victoriei \\ Bdv, 550500 Sibiu, Romania
}

\begin{abstract}
The transportation problem is becoming increasingly complex at a national, European and global level. Achieving an efficient and safe transportation system with low environmental pollution, with a quick delivery is a requirement for any carrier in the $21^{\text {st }}$ century. When talking about oversized transport, the challenge is even greater. Making a low loader go through several European countries has proved to be more complicated than we expected, due to the lack of uniformity of laws in this field. This paper seeks to find these different regularities characteristics from one European country to another and to propose developing procedures leading to the design and implementation of cheaper and faster oversized transport, with a lower environmental pollution and fewer human and material resources involved.
\end{abstract}

\section{Introduction}

Transportation is a technical and economic field in continuous development. As the production of goods is growing and desires of customers are becoming increasingly demanding, products must reach customers on tight deadlines, safely, with minimal costs, respecting the environmental conditions more restrictive.

The oversized transportation issue is more delicate. Special specifications are required for drivers, vehicles, infrastructure, special transportation permits, the maximum permitted dimensions, marking vehicles accompanying crews and more. Putting these specifications in full correlation, especially for the oversized transportation through many countries, and possibly multimodal regimen is a challenge that carriers and other economic factors, political and social must agree upon. To simplify the design and implementation of a low loader is a matter of creating an uniform communitarian law as well as creating European transport corridors, involving very diverse factors in decisions to implement such measures.

\section{Current state}

For a while there have been concerns in the European Comunity about the simplification of the process of oversized tranzit. The European Directive 96/53 establishes what are the

\footnotetext{
"Corresponding author: carmen.purcar@ulbsibiu.ro
} 
maximum admitted dimensions of oversized cargo the maximum authorized weights, and the maximum authorized axle loads.

In 2006 the European Commission issued guidelines on good practices for oversized vehicle transit in Europe. These guidelines, jointly developed by European sector experts, member states and EU Commission, are aimed at facilitating the effective performance of oversized transport within the territory of the EU, the enhancement of operations relating to this kind of activities and the introduction of greater transparency in the area of OC transport. One of the main issues in the guidelines is the designation of transportation corridors for oversized cargo. These corridors should comprise economically important roads included in the E-way programme, other motorways, roads leading to industrial areas, ports, container terminals etc. Information on such corridors should be available for all parties dealing with oversized transportation: carriers, police agents, permit issuing authorities, bodies responsible for building and maintaining bridges, roads, tunnels etc. That way the oversized vehicle operations could be carried out on roads best suited for the purpose, belonging to the road corridor network where simplified application procedures are used [1].

Issues related to the development of transport corridors in the southern Baltic Sea for the economic development of the area were studied [1]. A network of information and possible routes of local transportation were created. In the study, oversized transport in the southern Baltic Sea was started to highlight economically developed areas, considering the main recipients of goods produced, along with prospects for medium and long-term development. There were taken into account all transport options adjoining their infrastructure and development opportunities for each. All have led to the inclusion of new corridors in the Berlin Moscow corridor. There have been analyzed oversized tranzit problems on smaller areas such as Lithuania [2] or Baltic Sea area. There have been created networks containing the possible and disponible routes from some areas using the GIS systems [3]. It has also been attempted to optimize the route for the oversized traffic taking into account the radii of curvature of the track intersections (4).

UAB Omega Technology (Norway) established in Klaipeda Science and Technology Park (KSTP), together with KSTP are creating the OTIN system (Oversize Transport Information Network). This system will help transportation companies get information about oversized cargo transportation and obtain necessary permits [5]. The oversized transportation strategy is developed in order to create a unified regional approach (South Baltic region) for oversized cargo transportation procedures and to identify four key aspects of development: transportation corridors, legal framework, economic impact, and improvements of infrastructure and technology. The system is intended to integrate with existing systems in Sweden and Germany thus significantly improving the accessibility of permits issuing services. In countries where information systems were not adapted to support web services, the extended version of the system will be used, allowing to simplify the communication between the authorities and carriers. Following the implementation of the project the development of the system both in functional and geographical context is planned.

The problem with transportation increasing in size and weight was combined with that of the multimodal transport [6]. The general trend is to increase the permissible parameters of means of transport, including weight, while cargo should reach destinations increasingly remote. However, the solution also aims for increasing the speed of transport, minimizing costs, enhancing traffic safety, means of transport and volume of cargo loaded. In the past few years in Europe many studies and scientific papers have been written and many opinions of experts on the impact of transport LHV (Longer and Heavier Vehicles) on the transport market have been expressed. The studies were coordinated by European and national authorities, research institutes, organizations and associations involved in 
transport. Of course the conclusions of these studies are not absolute, they are the following:

- $\quad$ compared with standard road trucks, LHV transportation reduce costs by $15 \%$;

- $\quad$ LHV main transportion limitations come from the increase of fuel prices, several large salaries and maintenance costs;

- $\quad$ it is difficult to estimate the volume of freight transport over the LHV from rail operators on long distances at Community level;

- the highest costs related to the free movement of LHV are related to adapting infrastructure. These costs alone, will limit this transportion option for some countries.

Thus, the main transportation corridors to be used by LHV starts in Britain, through Benelux and Central Europe to Italy [6]. [7].

The oversized traffic can be regarded as a specific project logistics transport services,

In some parts of Europe there have been examined more heavy tranzit routes and the optimal route was chosen according to certain restritive conditions through criteria analysis [8].

Risk evaluation and management are one of the key issues during the planning of oversized goods safe transportation and investments into transport infrastructure reconstruction. Usually it is international transportation and decision-making that requires through analysis of the problem both, on the national and international scale and only then the most rational decision (transportation route) can be made taking into consideration the effective risk lowering. The objective of the risk evaluation when investing into infrastructure reconstruction is to safeguard heavyweight or oversized goods transportation. When making the quantitative and economic assessment of the risk, the theory of chances and mathematic statistics are the most commonly used methods, because they are denoted to describe an event or process in case of ambiguous possibilities [8].

It can be concluded that there are serious concerns for optimizing Community oversized transport, with many factors involved. Computer networks and databases for easier access to information that facilitate the design and implementation of this type of transport were created as a consequence. There are proposals for the realization of European transport corridors oversized: the southern Baltic Sea, Berlin - Moscow, Britain to Central Europe and Italy.

\section{Studies on implementing an oversized transportation system on the route Mokrice (Croatia) - Lulea (Sweden)}

Documentation on oversized shipments in Europe was imposed, inter alia the need for such transport on the route Mokrice (Croatia) - Lulea (Sweden). From the oversized transportation organization, it has emerged that the design and implementation of a European heavy transportation system are not so easy because non-uniformity of rules and documents is required from country to country. These problems lead to high costs, prolonged transport, inefficient use of human resources, financial resources and means of transportation. We have analyzed the documents required for transit in countries like Romania, Hungary, Croatia, Austria, Slovenia, Sweden, Lithuania, Germany, Czech Republic, Poland or the directly documentation to the competent authorities of some of these countries.

Documentation in order to obtain special permits carriers has been put together and it can highlight a number of differences between ways of obtaining them, which constitute the major issues identified in carrying oversized transport in the EU:

- between the settlement terms of a special transport permits (between 3 days in Sweden 
and 15 days in Slovakia and Germany);

- between the number of crew accompanying, an economic performing operator who will make specialized accompaniment and the number of persons involved;

- between a transport permits format and language completing;

- a crew accompanying police from the road service area (Slovenia - without police);

- differences in costs for special transport permits

- differences in affordability in terms of the number of trucks used based on a permit:

- one transport, one route, one assembly (Hungary, Romania);

- any transport a limited period (3 months Austria);

- for several ensembles in the same configuration defined by the number of axles of the tractor head and of the semi-trailer (Germany);

- in Austria the authorization shall be issued for semitrailer (you can use any tractor);

- differences in terms of validity:

- less than three months (Austria);

- $\quad$ six month (Poland);

- indicated by the carrier, within certain limits (Germany);

- one transport, one route from one assembly;

- transit country is achieved only with crew accompanying certificate under the law of that country (in Sweden may be accompanying crew from another country, a car to maximum three trucks);

- documents accompanying vehicles;

- marking conditions of the motor vehicle;

- responsibility for assessing accessibility route (artwork, height, undercrossing elements of road infrastructure and utilities);

- the existence and use of appliances for height reduction;

- conditions eliminate any obstacles on trails (who requires authorization from whom);

- additional means of signalization road in case of accidental stationary roadway;

- the reasons for their refusals permits;

- conditionings trails:

- avoid certain highways during holidays;

- correlate with specific timetables for other terminals (multimodal transport);

- conditioning periods:

- from Monday hour 9 am to Friday hour 3 pm;

- between 10 pm and 6 am;

- correlation with periods of traffic supported by other countries.

- coordination of transport made by:

- carrier;

- police;

- traffic director (private Sweden).

Perhaps the solution of these drawbacks is the set up of a "Single office for obtaining special transportation permits".

In our case, several variants of routes were chosen, used depending on the circumstances, constraints, the beneficiary wishes, deadlines, gauge cargoes etc.

Also, the difficulty of such a project emerges from a comparison between "theory and practice" between the calculations preceding transportation project and collected on site or truck tracking system. Often there are a lot of contingencies situations along the transport operation. 


\section{Route description}

Routes used were mostly known by drivers thanks to their experience. The first convoy was left to the most experienced drivers (transport recognition). To avoid problems, it was loaded with goods with insignificant exceeded gauge (the load was only $1 \mathrm{~m}$ longer than the loading, so overall $17.5 \mathrm{~m}$ ).

Following this transport it was discovered that on the border between Hungary and Slovakia, exactly between the exit of the M15 (Hungary) and rise on the A2 (Slovakia) rehabilitation works were being performed of the road and its path was hence suited only for normal weight cars with minimum dimensions of 3,40 $\mathrm{m}$ width.

The first route was regarded as the optimal route because tolls for trucks were small, costs of transport permits and accompanying cars were not raised even if in Slovakia and the Czech Republic the time to reach them was relatively high. The restrictions of movement along this path were normal.

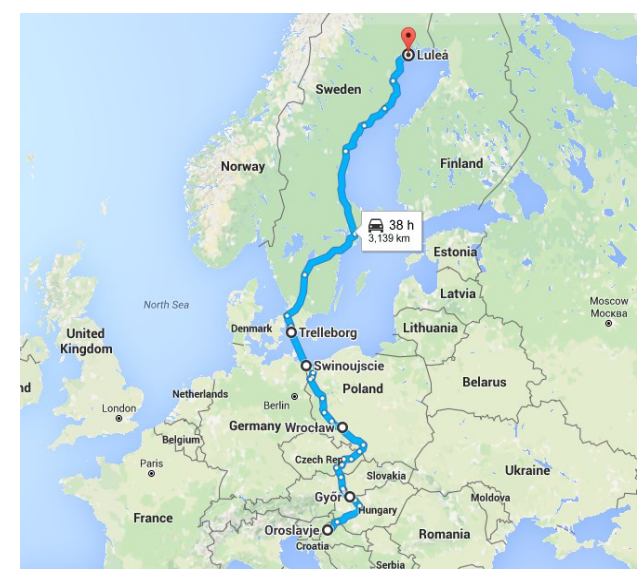

Fig. 1. Route 1 - Mokrice (Croatia) - Lulea (Sweden) via Gyor (Hungary) - Swinoujscie (Poland)

Following the findings of the first convoy yet another routewas adopted (Figure 2).

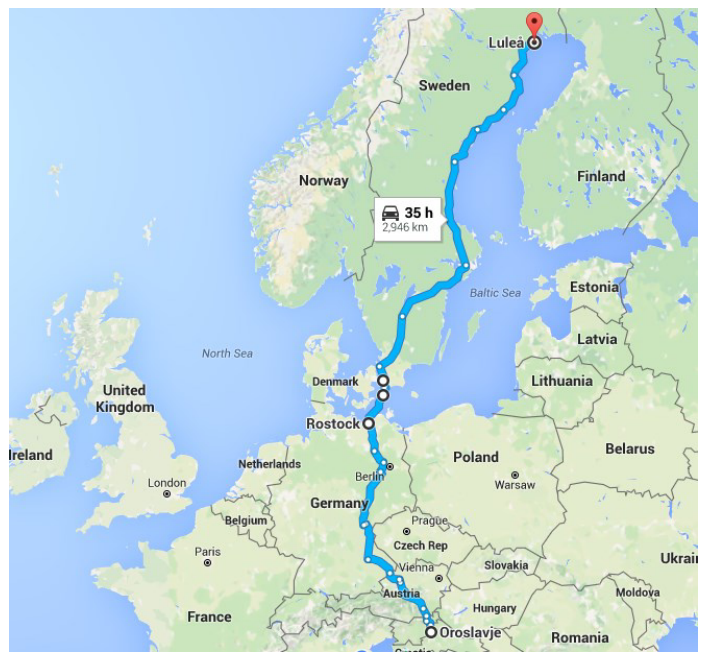

Fig. 2. Route 2 - Mokrice (Croatia) - Lulea (Sweden) via Austria-Rostock (Germany) 
To browse this route the trucks has to pass through: Croatia, Slovenia, Austria and Germany reaching the port of Rostock in northern Germany, a place where they would board the ferry and continued their course to the port of Trelleborg in Sweden

From a financial standpoint this route was not the best due to high costs of obtaining special transportation permits and accompanying cars. Even if the distance is shorter than the first route (about $180 \mathrm{~km}$ ), travel time was higher due to restrictions that impeded trucks to travel more than $600 \mathrm{~km}$ per night. Another factor that was considered a major impediment was represented by bureaucracy and the time for obtaining permits.

A particular problem was that the ferry reservation had to be made 3 days in advance. It was impossible to make a booking 3 days before because it meant that the place to be booked at the latest when the truck was loaded.

Along the way, many delays may have occured and this could have resulted in the loss of the reservation.

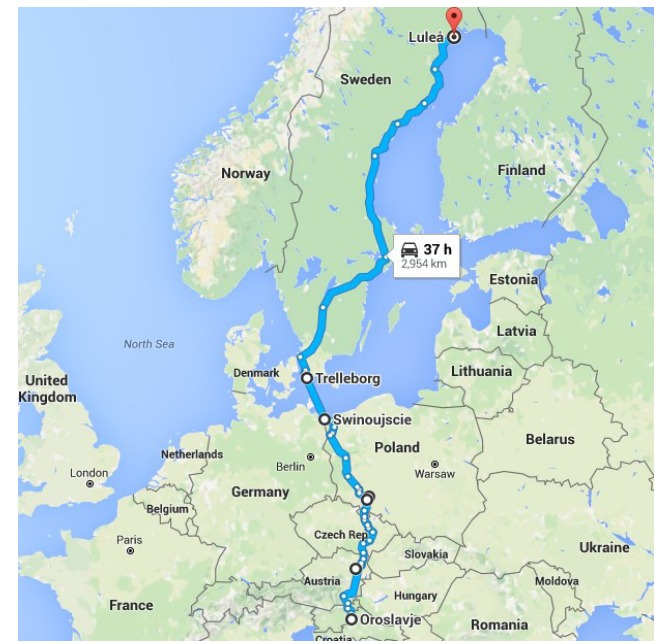

Fig. 3. Route 3 - Mokrice (Croatia) - Lulea (Sweden) via Austria - Czech Republic - Swinoujscie (Poland)

Also in Austria there is a succession of tunnels about to be closed in the opposite sense because their construction did not allow the passage of oversize trucks. Closing the tunnels was made after a specified timetable because the passage trucks overruns masses and dimensions is restricted during the day in Austria.

So, after the above was stated the need for a secondary route that were used when the seats were not found on ferryboat emerged (Figure 3). A third route would make a detour of Germany and of the tunnels in Austria. Transhipment ferryboat was made from Swinoujscie port (Poland) at the same port in Sweden, Trellerborg. Eventually it was found that this is the most effective route because of the existence of two daily ferry lines. Reservations must be made just a few hours before the arrival of the convoy to port. Also from a financial standpoint it was a mid-way solution with the best price - quality report in terms of transport permits, accompanying cars and ferries price, the difference in $\mathrm{km}$ being imperceptible.

Comparative presentation of the three routes is given in Table 1, showcasing the length, the costs and the limitations that apeared.

To choose between the three alternatives was considered appropriate performing a multi-criteria analysis [3], which takes into account the length of the route L, the duration $\mathrm{D}$, the total cost $\mathrm{C}$ and the route constaints Con. 
Table 1. Comparison between the three routes

\begin{tabular}{|c|c|c|c|c|c|c|}
\hline $\begin{array}{c}\text { Route } \\
\text { no. }\end{array}$ & $\begin{array}{c}\text { Transit } \\
\text { countries }\end{array}$ & $\begin{array}{c}\text { Length } \\
{[\mathrm{km}] /} \\
\text { Time } \\
\text { [hour] }\end{array}$ & $\begin{array}{c}\text { Cost } \\
\text { permit } \\
\text { transport }\end{array}$ & $\begin{array}{c}\text { Cost } \\
\text { accomp } \\
\text { anying } \\
\text { crew }\end{array}$ & $\begin{array}{c}\text { Road } \\
\text { tax }\end{array}$ & Limitation \\
\hline 1 & $\begin{array}{c}\text { via Gyor } \\
\text { (Hungary)- } \\
\text { Czech } \\
\text { Republic - } \\
\text { Swinoujscie } \\
\text { (Poland) }\end{array}$ & $3139 / 38$ & low & low & small & $\begin{array}{c}\text { - work rehabilitation } \\
\text {-road between } \\
\text { Hungary } \\
\text { and the Czech } \\
\text { Republic - } \\
\text { limitingwidth convoy } \\
\text { to normal size }\end{array}$ \\
\hline 2 & $\begin{array}{c}\text { via Austria - } \\
\text { Rostock } \\
\text { (Germany) }\end{array}$ & $2946 / 35$ & high & high & big & $\begin{array}{c}\text { - Trucks advancing no } \\
\text { more than } 600 \mathrm{~km} \text { per } \\
\text { night } \\
\text { - Ferry booking } 3 \\
\text { days before } \\
\text { - Transit tunnels in } \\
\text { Austria }\end{array}$ \\
\hline 3 & $\begin{array}{l}\text { via Austria - } \\
\text { Czech } \\
\text { Republic - } \\
\text { Swinoujscie } \\
\text { (Poland) }\end{array}$ & $2954 / 37$ & mediu & medium & medium & $\begin{array}{l}\text { - ferry reservation a } \\
\text { few hours before }\end{array}$ \\
\hline
\end{tabular}

The ranking criteria for carrier shows that the most important are D and Con while the last is L.

The calculation of the weights, acording to the multi-criteria analysis is presented in Table 2.

Table 2. The calculation of the weights

\begin{tabular}{|c|c|c|c|c|c|c|c|}
\hline & $\mathbf{L}$ & $\mathbf{D}$ & $\mathbf{C}$ & $\mathbf{C o n}$ & $\boldsymbol{\Sigma}$ points & Position & Weights \\
\hline $\mathbf{L}$ & $1 / 2$ & 0 & 0 & 0 & $1 / 2$ & 4 & 0,22 \\
\hline $\mathbf{D}$ & 1 & $1 / 2$ & 1 & $1 / 2$ & 3 & 1,5 & 3 \\
\hline $\mathbf{C}$ & 1 & 0 & $1 / 2$ & 0 & 1,5 & 3 & 1,14 \\
\hline Con & 1 & $1 / 2$ & 1 & $1 / 2$ & 3 & 1,5 & 3 \\
\hline
\end{tabular}

The weight on the last column was calculated using the formula (empirical) Frisco:

$$
\delta_{i}=\frac{p+\Delta p+m+0,5}{-\Delta p^{\prime}+\frac{N_{c r t}}{2}}
$$

where:

$\mathrm{p}$ is the sum of the points obtained on the line for the specific criteria;

$\Delta \mathrm{p}$ - the difference between the score of the considered element and theone from the last floor;

$\mathrm{m}$ - the number of outclassed criteria;

$\Delta \mathrm{p}^{\prime}$ - the difference between the score of the considered element and theone from the top floor;

$\mathrm{N}_{\text {crt }}$ - number of criteria.

Next, each variant will be granted for each criterion. Notes are between 1:10 and a higher grade means abetter appreciation of the journey across the criterion. Note 10 is the situation when option is perfect in terms of this criterion. 
In Table 3 there are analyzed the three alternatives in terms of weights and grades of the four criteria opposite.

Table 3. The final score of the three alternatives

\begin{tabular}{|c|c|c|c|c|c|c|c|}
\hline \multirow{2}{*}{ Criteria } & \multirow{2}{*}{ Weight } & \multicolumn{2}{|c|}{ Route 1 } & \multicolumn{2}{c|}{ Route 2 } & \multicolumn{2}{c|}{ Route 3 } \\
\cline { 3 - 8 } & & Note & Weight $\cdot$ Note & Note & $\begin{array}{c}\text { Weight } \cdot \text { Not } \\
\text { e }\end{array}$ & Note & $\begin{array}{c}\text { Weight } \text { Not } \\
\mathrm{e}\end{array}$ \\
\hline L & 0,22 & 6 & 1,23 & 10 & 2,2 & 8 & 1,76 \\
\hline D & 3 & 7 & 21 & 10 & 30 & 9 & 27 \\
\hline C & 1,14 & 10 & 11,4 & 8 & 9,12 & 9 & 10,26 \\
\hline Con & 3 & 7 & 21 & 5 & 15 & 10 & 30 \\
\hline & & & Sum $=54,63$ & & Sum $=56,32$ & & Sum $=69,02$ \\
\hline
\end{tabular}

As one can see, the third route is the one who has the greatest score, so that in these circumstances it is reasonable to choose it.

So it can be said that the planning of the route to move combinations of vehicles has been complicated due to several factors (some unforeseen at the beginning):

- drivers experience;

- temporary restrictions of road works;

- restrictions on busy roads during certain times (highways in times of holidays);

- costs of transportation permits and accompanying cars;

- time (and bureaucracy) of obtaining transportation permits;

- advancement restrictions of trucks at night;

- time of booking to boarding the ferryboat (overcrowded that time of year);

- restrictions to the gauge cargo (not all vehicle assemblies were loaded equally);

- restrictions to the gauge during transit and tunnels in Austria.

From the above, it can be concluded that the establishment of an optimal route from the start, it is almost impossible. A route is suitable for a given load, for certain gauge restrictions, for certain costs, for a certain period of the week, and another is optimal within other constraints.

\section{Conclusions}

Following the study, there can be mentioned some conclusions:

1. From the legal perspective there are major differences between the component countries of the European Union regarding oversized transportation. These differences largely disappear if a "Single office for obtaining special transportation permits" would be created. But setting up such an office requires:

- Uniform legislation throughout the European Union;

- Reducing settlement terms of permit applications;

- The set up of accompanying crews certified in all European Community countries;

- Creating unified toll crossing permits;

- The use of combinations of vehicles of different configurations in the same Pass;

- Use of foreign languages in completing requests for authorization to transport;

- Establishing uniform standard application for transport permits;

- The presence of a representative of each country participating in such shipments.

2. In terms of routes, it is impossible to choose one optimal route. Therefore alternative routes were used for each type of cargo.

3. A car park properly equipped is a great facility in terms of transportation costs because various cargo transportation with minimal cost bring a great financial benefit to the carrier. 
The information that the GPS system provides tracking of trucks is an option that carriers can not do without.

4. The GPS tracking of trucks, is an option that carriers can not do without.

5. Making a "Single office for obtaining special transportation permits" is a necessity that can ease the work and efficiency of transport carriers.

There is much talk of European corridors for carrying oversized transport, which is necessary and beneficial. We saw, however, that from the three routes used, each presented advantages and disadvantages, the most appropriate one variant or another, depending on certain temporary restrictions. There was performed a multi-criteria analysis, which takes into account the length of the route $\mathrm{L}$, the duration $\mathrm{D}$, the total $\operatorname{cost} \mathrm{C}$ and the route constraints Con. Finally, the third route variant was found to be most suitable and could be a portion of a corridor linking southern to northern Europe.

The European Community's Large companies for oversized transport may suggest possible efficient routes of European corridors, alongside with companies that produce oversized products, their beneficiaries, the factors responsible for the environment, other economic and political factors.

\section{References}

1. A. Galor, W. Galor, B. Wisnicki, http://www.transportoversize.eu/en/articles/id/4030/ Accessed 20.02.2017

2. R. Palsaitis, A. Petraska, Transp. and Telec. J, 13, 51 (2009)

3. Y. Li, T. Jerry, R. Danny et. Al. Mapping Oversized and Overweight Truck Routes with Procedure Based on Geographic Information Systems, 2291, 8-16, (2012)

4. M. Lingkui, H. Zheenghua, H. Changquing, W. Zhang., T. Jia. Int. Jour. of Geo-Information, 4, 2428-2445 (2015)

5. http://www.transportoversize.eu/en/articles/id/4026/ Accessed 15.11.2016

6. B. Wisnicki, W. Galor, http://www.transportoversize.eu/en/articles/id/4031/ Accessed 18.02.2017

7. I. Pisz, I. Lapunka. TranSopote Conference On Transport DevelopmentChallenges in the TwentyFirst Century. Book Series: Springer Proceedings in Bussines and Economics, 139-160 (2016).

8. A Petraska, R. Palsaitis, N. Batarliene, et. al. Transport Means - Proceedings of the International Conference, 236-239 (2011) 